\title{
Faktor- Faktor yang Mempengaruhi Ibu Nifas tentang Perdarahan Postpartum
}

\author{
Fitri Rachmania ${ }^{1}$, Lela Zakiah ${ }^{2}$ \\ 1,2 Akademi Kebidanan Prima Husada Bogor \\ Jln. Brigjen H. Saptadji No. 19, Cilendek Barat Bogor, Indonesia \\ Telp. (0251) 8319922 Email: lelazakiah07@ gmail.com
}

\begin{abstract}
Abstrak
Berdasarkan data 10 kasus terbanyak di RSUD Cibinong Kabupaten Bogor pada tahun 2016 tercatat pada rekam medik kasus perdarahan postpartum ada sebanyak 38 kasus dan pada tahun 2017 tercatat peningkatan perdarahan postpartum menjadi 102 kasus. Tujuan Penelitian ini dilakukan untuk mengetahui Faktor-Faktor Yang Mempengaruhi Ibu Nifas Tentang Perdarahan Postpartum di RSUD Cibinong Tahun 2017.Penelitian ini menggunakan metode desain survey analitik kualitatif dengan pendekatan Cross Sectional. Populasi sebanyak 1675 responden dan sempel sebanyak 94 responden ibu nifas yang mengalami perdarahan postpartum di RSUD Cibinong. Berdasarkan hasil penelitian, menunjukan bahwa dari total 94 responden ibu nifas yang tidak mengalami perdarahan postpartum, sebanyak $63(67,0 \%)$. berdasarkan umur tidak berisiko sebanyak $53(56,4 \%)$. berdasarkan paritas berisiko, sebanyak 51 (54,3\%). berdasarkan pendidikan rendah, sebanyak $53(56,4 \%)$. berdasarkan ibu yang tidak pekerjaan, sebanyak $80(85,1 \%)$. Simpulan ada hubungan antara umur dan paritas. Saran bagi tempat penelitian diharapkan dapat digunakan sebagai masukan dalam meningkatkan pelayanan kebidanan dan diharapkan kepada tenaga kesehatan tetap terus memperhatikan kelengkapan pendokumentasian data rekam medik pasien agar data- data pasien tercatat dengan lengkap dan rapih.
\end{abstract}

Kata kunci : Ibu Nifas, Perdarahan Postpartum

\begin{abstract}
Based on data from the 10 most cases in Cibinong Hospital, Bogor Regency, in 2016, there were 38 cases of postpartum haemorrhage in the medical record and in 2017 there was an increase in postpartum hemorrhage to 102 cases. The purpose of this study was to determine the Factors Affecting Postpartum Mother About Postpartum Bleeding in Cibinong Hospital in 2017. This study used a qualitative analytical survey design method with a cross sectional approach. With the number of samples as many as 94 respondents of postpartum mothers who experienced postpartum bleeding in Cibinong Hospital. Based on the results of the study, it was shown that of a total of 94 postpartum mothers who did not experience postpartum hemorrhage, 63 (67.0\%). based on age not as many as 53 (56.4\%). based on risky parity, as many as 51 (54.3\%). based on low education, $53(56.4 \%)$. based on mothers who do not work, as many as 80 (85.1\%). Conclusion There is a relationship between age, parity, education and postpartum mothers and there is no relationship between work and postpartum mothers. Suggestions for the place of research from the results of this study are expected to be used as input in improving midwifery services and it is expected that health workers will continue to pay attention to the complete documentation of patient medical records so that the patient's data is complete and neat.
\end{abstract}

Keywords: Postpartum Mother, Postpartum Hemorrhage, Influence 


\section{Pendahuluan}

Menurut data World Health Organitation (WHO) ${ }^{1}$ Angka kematian ibu pada tahun 2015 sebanyak 303.000 kematian ibu terjadi diseluruh dunia. Di Asia Tenggara perdarahan postpartum masih tergolong tinggi. Angka kematian ibu akibat perdarahan postpartum 359/100.000 kelahiran hidup diantaranya adalah atonia uteri 50-60\%, retensiao plasenta 23-29\%, robekan jalan lahir $4-5 \% .^{2}$

AKI di Indonesia bisa dikatakan masih tergolong tinggi jika dibandingkan dengan negara- negara di Asia Tenggara. Berdasarkan survei Millennium Devalopment Goals (MDG) pada tahun $2015^{3}$, kasus kematian ibu dan bayi baru lahir di indonesia masih pada posisi 305 per 100.000 kelahiran. Padahal target yang di rencanakan Perserikatan Bangsa-Bangsa (PBB) adalah 102 per 100.000 kelahiran. Sementara target dari Sustainnable Devalopment Goals (SDG) untuk angka kematian ibu adalah 70 per 100.000 kematian. di Indonesia sekitar 28\% kematian ibu disebabkan oleh perdarahan, 13\% Eklamsi atau gangguan akibat Hipertensi saat kehamilan, 9\% partus lama, 11\% komplikasi aborsi dan $10 \%$ akibat infeksi. Provinsi Jawa Barat sebagai salah satu provinsi dengan angka kematian ibu (AKI) tertinggi diindonesia berdasarkan laporan rutin profil kesehatan kabupaten/kota tahun 2015 tercatat jumlah kematian maternal yang terlaporkan sebanyak 799 orang (84,78/100.000 kelahiran hidup), dengan proporsi kematian pada ibu hamil 227 orang (20,09/100.000 kelahiran hidup), pada ibu bersalin 202 orang $(21,43 / 100.000$ kelahiran hidup), dan pada ibu nifas 380 orang (40,32/100.000 kelahiran hidup), jika dilihat berdasarkan kelompok umur presentai kematian berdasarkam kelompok umur <20 tahun sebanyak 71 orang $(8,89 \%)$, kelompok umur 20-34 tahun sebanyak 509 orang $(63,70 \%)$, dan $>35$ tahun sebanyak 219 orang $(27,41 \%){ }^{4}$

Upaya yang dilakukan untuk peningkatan pencapaian program penurunan angka kematian maternal, khususnya disebabkan oleh perdarahan post partum adalah peningkatan kapasitas tenaga kesehatan dalam penanganan kegawatdaruratan maternal, perbaikan infra struktur dan sistem rujukan, penyediaan sarana dan prasarana pendukung dan pemerataan distribusi tenaga kesehatan. Perdarahan postpartum adalah perdarahan yang masih aktif dan berasal dari tempat implantasi plasenta, robekan pada jalan lahir dan jaringan sekitarnya juga merupakan salah satu penyebab kematian ibu di samping perdarahan karena hamil ektopik dan abortus. ${ }^{5}$ Faktor resiko terjadinya perdarahan postpartum yaitu: usia, paritas, janin besar, riwayat buruk persalinan sebelumnya, anemia berat, kehamilan ganda, hidramnion, partus lama, partus presipitatus, penanganan yang salah pada kala III, hipertensi dalam kehamilan, kelainan uterus, infeksi uterus, tindakan operatif dengan anastesi yang terlalu dalam. $^{6}$

\section{Metode}

Penelitian ini menggunakan desain survey analitik kualitatif dengan pendekatan cross sectional. Populasi pada penelitian ini adalah seluruh ibu nifas di RSUD Cibinong kabupaten Bogor tahun 2017 sebanyak 1675 responden. Sampel yang didapatkan sebanyak 94 sampel. Cara pengambilan sampel pada penelitian ini adalah random sampling

\section{Hasil}

Tabel 1. Distribusi Umur, Paritas, Pekerjaan, Pendidikan dan Perdarahan Postpartum

\begin{tabular}{|c|c|c|}
\hline Variabel & (f) & $(\%)$ \\
\hline \multicolumn{3}{|c|}{ Perdarahan Postpartum } \\
\hline Ya & 31 & 33,0 \\
\hline Tidak & 63 & 67,0 \\
\hline \multicolumn{3}{|l|}{ Umur } \\
\hline Berisiko & 41 & 43,6 \\
\hline Tidak Berisiko & 53 & 56,4 \\
\hline \multicolumn{3}{|l|}{ Paritas } \\
\hline Berisiko & 51 & 54,3 \\
\hline Tidak Berisiko & 43 & 45,7 \\
\hline \multicolumn{3}{|l|}{ Pekerjaan } \\
\hline Tidak Bekerja & 80 & 85,1 \\
\hline Bekerja & 14 & 14,9 \\
\hline \multicolumn{3}{|l|}{ Pendidikan } \\
\hline Rendah & 53 & 56,4 \\
\hline Tinggi & 41 & 43,6 \\
\hline
\end{tabular}


Tabel 2. Hubungan Umur, Paritas, Pendidikan dan Pekerjaan terhadap Perdarahan Post Partum

\begin{tabular}{|c|c|c|c|c|c|c|c|c|}
\hline \multirow[t]{3}{*}{ Variabel } & \multicolumn{8}{|c|}{ Perdarahan Postpartum } \\
\hline & \multicolumn{2}{|c|}{$\mathbf{Y a}$} & \multicolumn{2}{|c|}{ Tidak } & \multicolumn{2}{|c|}{ Total } & \multirow{2}{*}{ OR } & \multirow{2}{*}{$P$ Value } \\
\hline & $\mathbf{n}$ & $\%$ & $\mathbf{n}$ & $\%$ & $\mathbf{n}$ & $\%$ & & \\
\hline Umur & & & & & & & & 0,048 \\
\hline Berisiko & 18 & 43,9 & 23 & 56,1 & 41 & 100 & 2,408 & \\
\hline Tidak Berisiko & 13 & 24,5 & 40 & 75,5 & 53 & 100 & & \\
\hline \multicolumn{9}{|l|}{ Paritas } \\
\hline Berisiko & 22 & 43,1 & 29 & 56,9 & 51 & 100 & 2,866 & 0,023 \\
\hline Tidak Berisiko & 9 & 20,9 & 34 & 79,1 & 43 & 100 & & \\
\hline \multicolumn{9}{|l|}{ Pendidikan } \\
\hline Rendah & 23 & 43,4 & 30 & 56,6 & 53 & 100 & 3,163 & 0,015 \\
\hline Tinggi & 8 & 19,5 & 33 & 80,5 & 41 & 100 & & \\
\hline \multicolumn{9}{|l|}{ Pekerjaan } \\
\hline Tidak Bekerja & 25 & 31,2 & 55 & 68,8 & 80 & 100 & 0,606 & 0,394 \\
\hline Bekerja & 6 & 42,9 & 8 & 57,1 & 14 & 100 & & \\
\hline
\end{tabular}

\section{Pembahasan}

\section{Umur}

Hasil penelitian diperoleh data bahwa ibu postpartum dengan umur berisiko, sebanyak 41 responden yang mengalami perdarahan postpartum dengan persentase $(43,6 \%)$ dan tidak mengalami perdarahan postpartum berdasarkan umur tidak berisiko, sebanyak 53 responden dengan persentase $(56,4 \%)$. Hasil penelitian ini sejalan dengan penelitian yang dilakukan oleh Retno $(2016)^{7}$ yang menyimpulkan bahwa sebagian ibu yang mengalami perdarahan postpartum berada pada umur berisiko ( $<20$ tahun dan $>35$ tahun). Umur berkaitan dengan kesiapan ibu dalam reproduksi. Menurut Depkes (2007) yaitu usia ibu hamil kurang dari 20 tahun lebih berisiko karena rahim dan panggul ibu belum siap bereproduksi dengan baik, sehingga perlu diwaspadai kemungkinan mengalami persalinan yang sulit dan keracunan kehamilan yang bisa berakibat terjadinya komplikasi persalinan. Sebaliknya jika terjadi kehamilan pada usia lebih dari 35 tahun kurang siap untuk menghadapi kehamilan dan persalinan cenderung mengalami perdarahan, hipertensi, obesitas, diabetes, mioma uterus persalinan lama dan penyakit-penyakit lainnya ${ }^{8}$.

\section{Paritas}

Hasil penelitian diperoleh bahwa ibu nifas berdasarkan paritas sebanyak $51 \quad(54,3 \%)$ memiliki paritas berisiko dan sebanyak 43 $(45,7 \%)$ memiliki paritas tidak berisiko. Hasil penelitian ini sesuai teori Saifuddin (2002) yaitu paritas mempunyai pengaruh terhadap kejadian perdarahan pasca persalinan karena pada setiap kehamilan dan persalinan terjadi perubahan pada serabut otot di uterus yang dapat menurunkan kemampuan uterus untuk berkontraksi sehingga sulit untuk melakukan penekanan pada pembuluh-pembuluh darah yang membuka setelah lepasnya plasenta ${ }^{9}$. Hasil penelitian sesuai penelitian Megasari (2013) bahwa Ibu yang paritas >3 beresiko mengalami perdarahan pasca persalinan dibandingkan ibu yang paritasnya $2-3^{10}$.

\section{Pendidikan}

Hasil penelitian diperoleh bahwa ibu nifas berdasarkan pendidikan sebanyak $53(56,4 \%)$ memiliki pendidikan rendah dan sebanyak 41 $(43,6 \%)$ memiliki pendidikan tinggi. Sesuai dengan teori menurut Suaratin (2001) yaitu tingkat pendidikan yang tinggi akan menjadikan kehamilan lebih aman. Ibu dengan pendidikan tinggi cenderung menikah pada usia lebih tua, menunda kehamilan, mau mengikuti keluarga berencana (KB) dan mencari pelayanan antenatal dan persalinan. Disamping itu ibu dengan pendidikan rendah juga tidak akan mencari pengobatan tradisional bila hamil/bersalin dan juga dapat memilih makanan yang bergizi ${ }^{11}$. Hasil penelitian sesuai penelitian Megasari (2013) Ibu yang pendidikannya rendah beresiko mengalami perdarahan pasca persalinan 2 kali dibandingkan ibu yang pendidikan tinggi ${ }^{10}$.

\section{Pekerjaan}

Hasil penelitian diperoleh bahwa ibu nifas berdasarkan pekerjaan di RSUD Cibinong tahun 2017 menunjukkan bahwa dari total 94 responden yang mengalami perdarahan postpartum yaitu ibu yang tidak bekerja 
sebanyak $80(85,1 \%)$. Hasil penelitian sejalan dengan penelitian Arthina (2015) bahwa responden yang tidak bekerja atau IRT yang mengalami perdarahan lebih tinggi dibandingkan dengan ibu yang bekerja, karena selain mengerjakan pekerjaan rumah ibu juga harus membantu suami bekerja sehingga ibu mendapat peran ganda yaitu selain mengurus rumah tangga ibu juga bekerja ${ }^{12}$.

\section{Hubungan `antara Umur Ibu Nifas dengan Perdarahan Postpartum}

Hasil uji statistik dengan menggunakan uji chi-square didapat nilai Pvalue 0.048 yang artinya Pvalue $>0,05$, maka Ho diterima Odd Ratio pada penelitian ini didapatkan hasil 2,408. Hasil penelitian ini sejalan dengan penelitian yang dikakukan oleh Retno (2016) ${ }^{7}$, didapatkan hasil nilai pvalue $0,016<0,05$ yang artinya umur berpengaruh secara signifikan dengan kejadian perdarahan postpartum. Nilai OR sebesar 0,316 yang berarti ibu dengan umur berisiko memiliki peluang 0,316 kali untuk mengalami perdarahan postpartum. sesuai dengan penelitian Zenita (2015) yang menyatakan ada hubungan yang signifikan antara umur ibu dengan kejadian perdarahan pasca persalinan primer dan sekunder ${ }^{13}$. Kehamilan di usia kurang dari 20 tahun dan di atas 35 tahun bisa mengakibatkan anemia, karena pada usia kurang dari 20 tahun secara biologis belum optimal, emosi masih cenderung labil, sedangkan pada usia lebih dari 35 tahun terkait dengan penurunan daya tahan tubuh serta berbagai penyakit kronis yang menyebabkan anemia. Pengaruh anemia adalah kontraksi uterus yang lemah pada saat persalinan, dan juga plasenta lebih lekat karena kompensasi anemia yang berakibat sukar lepas, sehingga keadaan tersebut dapat mengakibatkan terjadinya perdarahan pasca persalinan ${ }^{14}$.

\section{Hubungan antara Paritas Ibu Nifas dengan Perdarahan Postpartum}

Hasil uji statistik dengan menggunakan uji chi-square didapat nilai $P$ value 0.023 yang artinya $P$ value $>0,05$, maka Ho diterima. Odd Ratio pada penelitian ini didapatkan hasil 2,866. Hasil penelitian ini sejalan dengan penelitian Friyandini, Lestari, dan Utama (2015) yang menyatakan bahwa tidak terdapat hubungan yang bermakna antara perdarahan postpartum primer dan sekunder dengan paritas dengan nilai $\mathrm{p}=0,953$ yaitu $\mathrm{p}>\alpha$ $(\alpha=0.05)$. Dalam penelitian ini terdapat hubungan antara paritas dengan perdarahan postpartum akan tetapi hasil $\mathrm{OR}=0,351$, OR < 1 menunjukkan bahwa paritas bukan merupakan faktor penyebab perdarahan postpartum, hal ini dapat dipengaruhi oleh beberapa faktor diantaranya yaitu paritas bukan merupakan faktor langsung yang menyebabkan perdarahan postpartum, selain itu sebagian besar responden pada penelitian ini berada pada paritas tidak berisiko (2-3) dengan angka $57,5 \%$. Hasil penelitian ini tidak sejalan dengan penelitian yang dilakukan oleh Retno $(2016)^{7}$, didapatkan hasil nilai pvalue $0,959<0,05$ yang artinya paritas tidak berpengaruh secara signifikan dengan kejadian perdarahan postpartum. Berarti dapat dinyatakan bahwa tidak terdapat hubungaan antara paritas dengan perdarahan postpartum ${ }^{15}$. Hasil penelitian ini tidak sejalan dengan penelitian yang dilakukan oleh Widianti \& Setiyaningsih (2014) yang menyatakan bahwa penelitiannya tersebut terdapat hubungan yang sangat signifikan antara jarak kehamilan dengan perdarahan pasca persalinan ${ }^{16}$. Pada saat interval kehamilan terlalu jauh berkaitan dengan umur maternal yang semakin bertambah, dengan bertambahnya usia maka saat persalinan kekuatan fungsi otot-otot uterus dan otot panggul melemah. Interval pada kehamilan yang jauh pengaruhnya hampir sama seperti pada persalinan primipara ${ }^{17}$.

\section{Hubungan antara Pendidikan Ibu Nifas dengan Perdarahan Postpartum}

Hasil uji statistik dengan menggunakan uji chi-square didapat nilai $P$ value 0.015 yang artinya $P$ value $>0,05$, maka Ho diterima Odd Ratio pada penelitian ini didapatkan hasil 3,163 Hasil penelitian ini sejalan dengan penelitian yang dilakukan oleh Megasari di RSUD Arifin Achmad Propinsi Riau tahun 2010 Uji Chi-Square menunjukkan bahwa nilai pvalue $0,001<0,05$ sehingga dapat dinyatakan bahwa terdapat hubungan antara pendidikan dengan perdarahan postpartum ${ }^{10}$. Hasil penelitian ini tidak sejalan dengan penelitian yang dilakukan oleh Retno $(2016)^{7}$, didapatkan hasil nilai pvalue $0,290<0,05$ yang artinya pendidikan tidak berpengaruh secara signifikan dengan kejadian perdarahan postpartum. Berarti dapat dinyatakan bahwa tidak terdapat 
hubungaan antara pendidikan dengan perdarahan postpartum.

\section{Hubungan antara Pekerjaan Ibu Nifas dengan Perdarahan Postpartum}

Hasil uji statistik dengan uji chisquare didapat nilai Pvalue 0.394 yang artinya Pvalue $>0,05$, maka Ho ditolak Odd Ratio pada penelitian ini didapatkan hasil 0,606. Hasil penelitian ini sejalan dengan penelitian yang dilakukan oleh Retno (2016) ${ }^{7}$, didapatkan hasil nilai pvalue $0,091<0,05$ yang artinya pekejaan tidak berpengaruh secara signifikan dengan kejadian perdarahan postpartum. berarti dapat dinyatakan bahwa tidak terdapat hubungaan antara pekerjaan dengan perdarahan postpartum. Hasil Penelitian ini tidak sejalan dengan penelitian Arthina (2015) bahwa ada Hubungan Pekerjaan dengan Kejadian Perdarahan Postpartum di RSUD Panembahan Senopati Bantul Yogyakarta Tahun 2013-2014.

\section{Kesimpulan}

Berdasarkan hasil penelitian dan pembahasan tentang Faktor- Faktor Yang Mempengaruhi Ibu Nifas Tentang Perdarahan Postpartum di RSUD Cibinong Tahun 2017 Kabupaten Bogor sebanyak 94 resonden terdapat $63(67,0 \%)$ yang tidak mengalami perdarahan postpartum, $53 \quad(56,4 \%)$ mengalami perdarahan postpartum dengan umur tidak berisiko sebanyak 51 (54,3\%).

Mengalami perdarahan postpartum dengan paritas berisiko, pendidikan rendah sebanyak 53 (56,4\%), yang mengalami perdarahan postpartum dengan ibu tidak bekerja sebanyak $80 \quad(85,1 \%)$. Terdapat hubungan antara umur dengan pengaruh ibu nifas tentang perdarahan postpartum di RSUD Cibinong tahun 2017, terdapat hubungan antara paritas dengan pengaruh ibu nifas tentang perdarahan postpartum di RSUD Cibinong tahun 2017. Ada hubungan antara pendidikan dengan pengaruh ibu nifas tentang perdarahan postpartum di RSUD Cibinong tahun 2017.

\section{Saran}

Saran dalam penelitian ini adalah bagi tempat penelitian hasil penelitian ini diharapkan dapat digunakan sebagai masukan dalam meningkatkan pelayanan kebidanan dan diharapkan kepada tenaga kesehatan harus memperhatikan kelengkapan pendokumentasian data rekam medik pasien tercatat dengan lengkap.

\section{Daftar Pustaka}

1. WHO; 2015.

2.Manuaba, Ayu Ida C.H Bagus, Ida G.F.Manuaba, Ida Bagus Manuaba. Ilmu Kebidanan, Penyakit Kandungan, dan KB.Jakarta: EGC; 2010.

3. MDGS. 2015

4. KEMENKES Jawa Barat.2016

5.Prawirohadjo S. Acuan Nasional Pelayanan Kesehatan Maternal dan Neonatal. Yayasan Bina Pustaka; Jakarta; 2008.

6.Lestrina \& Eny .Hubungan Antara Paritas dan Anemia Dengan Kejadian Perdarahan Post Partum Di Rumah Sakit William Booth Surabaya Periode 2007-2012. Volume 1 Nomor 1 (2012).

7.Retno A. "Faktor- Faktor Yang Mempengaruhi Kejadian Perdarahan Postpartum Di RSUD Sekarwangi Tahun 2016" dalam Jurnal Kesehatan Komunitas, Vol 1 (Hlm 36-40) Bogor: Akbid Prima Husada Bogor; 2018.

8.Departemen Kesehatan RI. Direktorat Jenderal Binkesmas Profil Kesehatan Indonesia Tahun 2005. Jakarta; 2007.

9.Saifuddin, A.B, dkk, Buku Acuan Nasional Pelayanan Kesehatan Maternal dan Neonatal. Jakarta : Yayasan Bina Pustaka Sarwono Prawirohardjo; 2002.

10.Megasari, Miratu. "Faktor-faktor yang Berhubungan dengan Kejadian Perdarahan Pasca Persalinan di RSUD Arifin Achmad Propinsi Riau Tahun 2009-2010" dalam Jurnal Kesehatan Komunitas, Vol. 2 (hlm 77 ). Pekanbaru: Prodi Kebidanan STIKes Hang Tuah Pekanbaru; 2013.

11. Suaratin. Faktor yang Mempengaruhi Kematian Ibu Akibat Perdarahan Pasca Persalinan di RSU. Kabupaten Tanggerang tahun 19972000.Tesis S2 UI. Jakarta: 2001.

12.Arthina, Baiq Nini. Hubungan Pekerjaan dengan Kejadian Perdarahan Postpartum di RSUD Panembahan Senopati Bantul Yogyakarta Tahun 2013-2014: 2015.

13.Zenita okta SF. Faktor-Faktor yang Berhubungan dengan Perdarahan Postpartum di RSUD Dr.Soeroto Ngawi Jawa Timur Tahun 2013. Jurnal Ilmiah Kesehatan. 2015;7(1).

14.Sulistiyani CN. Hubungan antara Paritas dan Umur Ibu dengan Kejadian Perdarahan Post Partum di RS. Panti Wilasa "Dr. Cipto" Yakkum cabang semarang. Semarang. Jurnal Keperawatan dan Kebidanan (JIKK). 2010;1(2).

15. Friyandini, F. Lestari, Y. dan Utama, Bobby Indra. Hubungan Kejadian Perdarahan Postpartum dengan Faktor Risiko Karakteristik Ibu di RSUP Dr. M. Djamil Padang pada Januari 2012 - April 2013, Jurnal Kesehatan 
Andalas,

$2015 ; 4(3)$

dalam

http://jurnal.fk.unand.ac.id. 2015.

16. Widianti EY, Setiyaningsih A. Hubungan Jarak Kelahiran dengan Kejadian Perdarahan Postpartum Primer di BPS Hermin Sigit Ampel Boyolali. Jurnal Kebidanan; 2014;6(1):22-28.
17. Yuliyati A, Soejoenoes A, Suwondo A, Anies, Irene KM. Beberapa faktor kejadian perdarahan postpartum ibu bersalin yang dirawat di rumah sakit. Semarang: Program Studi Magister Epidemiologi Sekolah Pasca Sarjana Universitas Diponegoro; 2017. 